\title{
Seasonal Growth and Spatial Distribution of Apple Tree Roots on Different Rootstocks or Interstems
}

\author{
Li Ma \\ Institute of Horticultural Plants, China Agricultural University, 2 Yuanmingyuan West Road, Haidian \\ District, Beijing 100193, P.R. China; and the Department of Life Science, Shangqiu Normal \\ University, 298 Wenhua Road, Liangyuan District, Shangqiu, Henan Province, 476000, P.R. China
}

Chang Wei Hou, Xin Zhong Zhang, Hong Li Li, De Guo Han, Yi Wang, and Zhen Hai Han ${ }^{1}$

Institute of Horticultural Plants, China Agricultural University, 2 Yuanmingyuan West Road, Haidian District, Beijing 100193, P.R. China

\begin{abstract}
Additional INDEX words. dwarfing rootstock, Malus $\times$ domestica, minirhizotron, root length density
Abstract. Understanding of root growth patterns and architecture of apple (Malus $\times$ domestica Borkh.) trees is very important for commercial apple production. Most commercial apple trees are usually a grafted complex consisting of the scion and the rootstock, each of which is a different genotype. Recently, rootstocks of dwarf tree species have been used extensively to meet the convenience in management; however, this practice appears to negatively impact root development. Using minirhizotrons, we investigated root dynamics, root spatial distribution, and shoot growth in 'Red Fuji' scion grown: 1) directly on dwarf and vigorous root stocks and 2) on a dwarf root stock placed in between the non-dwarf scion and non-dwarf rootstock (hereinafter referred to as an interstem). The results showed that: 1) one or two peaks in total root length density (TRLD) were observed in each scion/rootstock combinations every year; 2) the greatest TRLD peaks were always observed in between May and December. The peaks of shoot growth were always asynchronous with that of white root length density; 3) compared with scion/vigorous rootstock combinations, inserting a dwarfing interstem between the scion and vigorous seedling rootstock reduced the TRLD; 4) scion/ vigorous rootstock combinations had a relatively deep, widespread and large root system. Scion/dwarfing rootstock combinations had a root system distributed in a small region; and the root systems of scion/dwarfing interstem/ vigorous rootstock combinations tended to be intermediate between those of scion/vigorous rootstock and scion/ dwarfing rootstock. This implies that the insertion of interstems altered the root architecture by not only the quantity of roots, but also the spatial distribution.
\end{abstract}

The root system anchors the plant and is the organ chiefly responsible for water and nutrient absorption and the synthesis of many endogenous hormones. The root system affects many processes such as the growth of new shoot branches and leaves, carbon assimilation, flower bud differentiation, and fruit development (Hodge et al., 2009; Malamy, 2005; Matamala et al., 2003; Xiao et al., 2008). Most commercially used apple trees are actually a grafted complex consisting of at least two genotypes, the scion and the rootstock. The extensive use of dwarfing apple rootstocks has launched a major shift into highdensity cultivation since the pioneering innovation of the East Malling series of dwarfing rootstocks (Jackson, 1989; Norelli et al., 2003). In apple and many other fruit tree species, dwarfing rootstocks significantly impact not only the tolerance and resistance to biotic and abiotic stresses, but also the growth of shoots in the canopy, fruit yield, and quality (Li et al., 2004; Sarwar et al., 1998; Wang et al., 1994; Welander, 1988). Dwarf apple trees have several advantages compared with vigorous stock that result from reduced vegetative growth. They take up less room and can be planted close together to give good yields (Jackson, 1989); the reduced size requires lower volumes of

Received for publication 18 May 2011. Accepted for publication 17 Dec. 2012. This project was supported by the National Special Funds for Scientific Research on Public Causes (Agriculture) Project nyhyzx07-024; the Modern Agricultural Industry Technology System (Apple); and the Key Laboratory of the Beijing Municipality of Stress Physiology and Molecular Biology for Fruit Trees.

We thank MuDan Yuan and Olivia Yue for their critical review of the manuscript. ${ }^{1}$ Corresponding author. E-mail: rschan@cau.edu.cn. expensive pesticides and less labor for pruning and training (Goedegebure, 1978; Werth, 1978, 1981). Additionally, they produce fruit earlier and the size and color of the fruits are uniform (Sarwar et al., 1998); however, roots of dwarf apple trees are often not as well developed as in vigorous stock (De Silva et al., 1999; Ma et al., 2010). Knowledge of root development and the spatial distribution of dwarfing rootstocks as well as an understanding of the relationship between the development of roots and shoots will thus be of great significance for the apple and fruit industries.

In very young orchards, the root distributions of non-dwarf apple trees (Hughes and Gandar, 1993) and kiwifruit (Actinidia Lindl.) vines (Gandar and Hughes, 1988) are bowl-shaped with the roots centered near the stem, whereas older trees have a more layered structure with a higher root length density (RLD) further away from the trunk (De Silva et al., 1999). Annual dynamics of root growth vary depending on the plant types. A study of 13-year-old 'Golden Delicious' apple trees indicated that root growth had three annual peaks and alternated with shoot growth (Qu and Han, 1983). Previous research has shown that year-on trees had two peaks of root growth (Wang, 2005), whereas the root dynamics of newly grafted apple trees ('Golden Delicious'/'M.9') (Atkinson, 1980) and potted young apple trees ('Starkrimson'/Malus Xmicromalus Makino) had a single peak of annual root growth (Wang et al., 1997).

Special techniques are required to observe root system spatial distribution, turnover, and growth (Vogt et al., 1998). Root spatial distribution and growth characteristics have usually been determined by destructive sampling techniques 
such as soil coring, in-growth cores, whole root-system excavation, and trenching (Johnson et al., 2001; Wu et al., 2005). The conventional underground observation chambers were used to analyze root systems through glass plates $(\mathrm{Qu}$ and Han, 1983; Wang et al., 1997). More recently, nondestructive techniques, including rhizotrons and minirhizotrons, have been used to observe the roots in situ and directly through the transparent minirhizotron tubes (Johnson et al., 2001). These methods permit the simultaneous acquisition of root production and disappearance information along with the investigation of root growth dynamic changes, which cannot be accomplished using traditional techniques (Majdi and Kangas, 1997).

Pregitzer et al. (2002) showed that fine roots have often been studied according to arbitrary size classes (e.g., roots 0 to 1 or 0 to $2 \mathrm{~mm}$ in diameter). Usually, fine roots are the roots less than $2 \mathrm{~mm}$ in diameter and include mycorrhizae (Zhang et al., 2000). Fine roots are an important and dynamic component of all terrestrial ecosystems. Fine roots can account for a significant portion of ecosystem net primary productivity (Pregitzer et al., 2002; Tufekcioglu et al., 1999). Fine root length appears to be a better index for determining root production and loss when compared with other root indices (Johnson et al., 2001). The following study used minirhizotron, which allows the nondestructive in situ examination of roots to observe root growth and to study the fine root distributions and architectures of apple trees. We discuss the root-shoot relationship in apple trees through an analysis of shoot and root growths. Our objective was to clarify the seasonal growth traits of apple tree fine roots growing on different rootstocks or interstems over two growing seasons and to estimate the effects of rootstock type on spatial distribution of apple tree roots.

\section{Materials and Methods}

FACILITy AND EQuipment. To obtain detailed data about the root development and architecture of fruit trees, $10[1.5 \times 1.5 \times$ $3 \mathrm{~m}$ (length $\times$ width $\times$ height)] rhizoboxes were constructed in a greenhouse. The bottom and the side walls of each rhizobox were built of reinforced concrete, and there were eight drains at the bottom of each rhizobox to avoid flooding caused by unintended overirrigation. A $1.5 \times 1.5 \times 1-\mathrm{m}($ length $\times$ width $\times$ height) space was available to store the water that oozed from the drains without filling the soil below each rhizobox. The roofs of the rhizoboxes were left open, and the top edges of the side walls were $10 \mathrm{~cm}$ above the floor of the greenhouse.

Five layers of minirhizotron tubes $(178 \mathrm{~cm}$ long, $5.6 \mathrm{~cm}$ diameter) were pre-installed horizontally before the rhizoboxes were filled with the growing substrate. The open terminus of a minirhizotron tube passed across the side wall, through a predrilled hole, and the distal end of the tube was embedded into the wall of the opposite side. Soil layers one to five were -20 , $-60,-100,-150$, and $-200 \mathrm{~cm}$ from the floor, respectively. Each of the five layers contained four tubes for a total of 20 tubes in each rhizobox. The four minirhizotron tubes in each layer were fixed along the same layer symmetrically against the central axis and parallel to each other with $37.5 \mathrm{~cm}$ between the tubes. Therefore, the two tubes on the same side of the tree were 18.75 and $56.25 \mathrm{~cm}$ in horizontal distance from the trunk of the tree, respectively (Fig. 1).

The rhizoboxes were filled with a growing substrate composed of garden soil, peat, and vermiculite (3:1:1 by volume) because natural soil structure was difficult to simulate in the

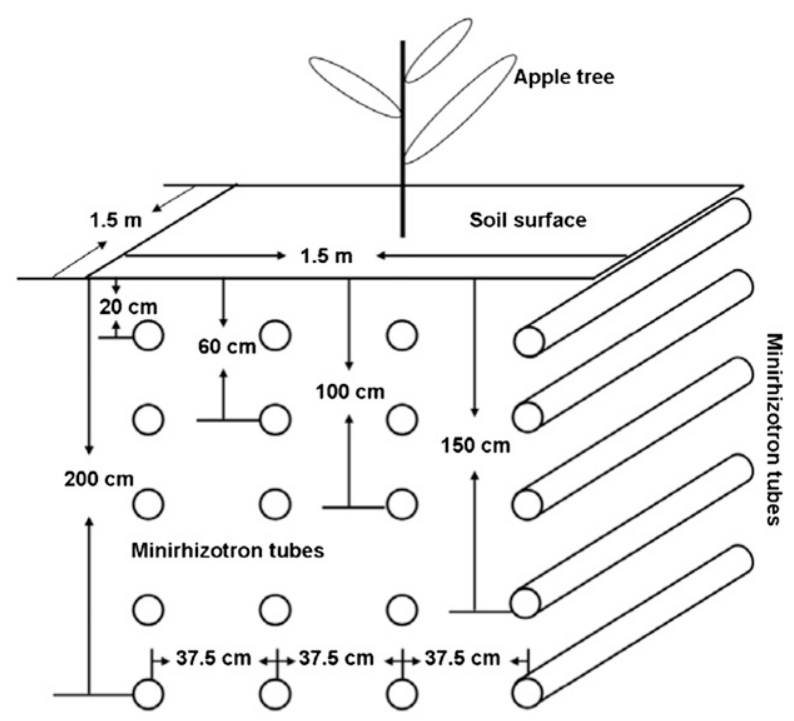

Fig. 1. Distribution of minirhizotron tubes in a rhizobox containing one apple tree. Five layers of minirhizotron tubes were installed horizontally in the rhizobox $[1.5 \times 1.5 \times 3 \mathrm{~m}$ (length $\times$ width $\times$ height $)]$ at $-20,-60,-100,-150$, and $-200 \mathrm{~cm}$ from soil surface, respectively. Each layer contained four tubes (20 tubes in each rhizobox) were fixed along the same layer symmetrically and parallel to each other with $37.5 \mathrm{~cm}$ between the tubes.

rhizoboxes. Garden soil was excavated from the 0 to $-30 \mathrm{~cm}$ plough layer of the vegetable garden, and it presumably contained diverse microbial species. Peat was used to increase soil organic matter; and vermiculite was used to improve soil porosity. The mixed substrate contained $44.5 \mathrm{~g} \cdot \mathrm{kg}^{-1}$ organic matter, $1.4 \mathrm{~g} \cdot \mathrm{kg}^{-1}$ total nitrogen, $40.8 \mathrm{mg} \cdot \mathrm{kg}^{-1}$ available phosphorus, and $92.0 \mathrm{mg} \cdot \mathrm{kg}^{-1}$ available potassium with $\mathrm{pH} 7.07$. The substrate was sieved to $2 \mathrm{~mm}$ and homogenized, and rocks were removed before it was packed into the rhizoboxes. The substrate was fully compacted with repeated flood irrigation before the plants were transplanted, and the soil surface was kept flush with the floor of the greenhouse.

Plant materials and management. The five scion/rootstock combinations of 'Red Fuji' (RF)/Malus prunifolia (Willd.) Borkh. 'Baleng Crab' (BC), RF/'M.9' (M.9), RF/ M.9/BC, RF/Shao series no. 40 (SH.40)/BC, and RF/SH.40 were grafted and potted in mid-Mar. 2009. The rootstocks' genetic background, country of origin, and specific characteristics are listed in Table 1 . The rootstock treatments (RF/ M.9, RF/SH.40, RF/BC) were grafted with 10-cm rootstock sections, and the interstem treatments (RF/M.9/BC, RF/ $\mathrm{SH} .40 / \mathrm{BC})$ were grafted with $10-\mathrm{cm}$ rootstock sections and $25-\mathrm{cm}$ interstem sections. M.9 and SH.40 rootstocks are dwarfing rootstocks; $\mathrm{BC}$ is a vigorous rootstock. Trees were chosen within each of the grafted combinations, which had similar stem caliper and height. One tree was transplanted in the center of each rhizobox on 23 May 2009. Two replicates of each treatment combination were performed. Each replication combination was in an east-west row and one tree per pit. Therefore, two replication combinations were in the south and north rows, respectively. The trees were pruned as thin spindles with the young branches growing upward pruned away on 1 May 2010. Conventional disease/pest management was used. The temperature of the greenhouse was maintained below $35^{\circ} \mathrm{C}$ during the growing seasons and at 5 to $15^{\circ} \mathrm{C}$ during dormancy. 
Table 1. The apple rootstocks used in this study of genetic diversity.

\begin{tabular}{llll}
\hline Rootstock & \multicolumn{1}{c}{ Parentage } & Country of origin & Specific characteristic \\
\hline M.9 & Malus pumila Mill. var. paradisiaca $($ L.) C.K. Schneider & United Kingdom & Dwarf \\
SH.40 & Malus honanensis Rehder $\times$ Malus $\times$ domestica Borkh. & China & Extreme dwarf \\
BC & Malus prunifolia (Willd.) Borkh. & China & Vigor \\
\hline
\end{tabular}

The glass house had adumbral nets on the roof, and the vertical ventilation and cooling combination of "damp curtainventilator" was adopted to avoid overly high temperatures during the summer, whereas a heating apparatus was installed to avoid the temperature too low during the winter. The adumbral nets, cooling combination, and heating apparatus were automatic controlled by a computer. The plants were irrigated by drip irrigation once every 2 weeks during the summer and once every 3 weeks during the other seasons. Four emitters were evenly placed around each plant at a $45-\mathrm{cm}$ distance from the trunk providing $\approx 80 \mathrm{~L}$ per plant during each irrigation.

Data Collection. Roots were observed with a minirhizotron system (ET100; Bartz Technology, Carpinteria, CA). Placement of tubes was initially assessed in three directions: $60^{\circ}$ to vertical direction facing the plant, the vertical direction, and $60^{\circ}$ to vertical direction back toward the plant. Most roots could be observed in the first direction $\left(60^{\circ}\right.$ to vertical direction facing the plant); therefore, this direction was chosen for the experiment. Data were collected from 2 Aug. 2009 to 10 Dec. 2010. We observed root growth weekly from 2 Aug. 2009 to 12 Jan. 2010 and once every 2 weeks during dormancy (12 Jan. to 1 May 2010) and once every $10 \mathrm{~d}$ during the rest of 2010 based on the results from 2009. There were a total of 50 observations. The view field of the digital camera used with the ET-100 minirhizotron system was $1.8 \times 1.35 \mathrm{~cm}$. Images were captured one by one every $1.35 \mathrm{~cm}$ along the tube for a total of 98 captures per tube, and a maximum of $98 \times 20$ images was obtained from each plot. All images were analyzed, and the root data were measured using the WinRHIZO TRON image analysis software (Regent Instruments Canada, Quebec, Canada). The root properties were defined as white, brown, and gone. White and brown roots were distinguished by the root colors shown in the images. Roots defined as "gone" were those that were no longer visible after having existed in an image gathered from the same place at an earlier time. The root length, surface area, diameter, volume, and number of tips were measured using WinRHIZOTRON. Root length is a more sensitive metric for dynamic root properties (Johnson et al., 2001), so only the length data are used in this article.

Total shoot length (centimeters) of each grafted combination was measured every $10 \mathrm{~d}$ throughout the growing season and then the shoot growth rate (centimeters per day) in early, middle, and late of every month was calculated.

Calculation of Root length Density. The RLD was estimated as the total length of roots (meters) per unit volume of soil (cubic meters) sampled. It was calculated by the equation $R L D=L /(n A \times S T)$, where RLD is the root length density (meters per cubic meter), $\mathrm{L}$ is the total length of roots (meters), $\mathrm{n}$ is the number of root images observed, $\mathrm{A}$ is the area of each visible window [square meters $\left(A=18.0 \times 13.5 \times 10^{-6} \mathrm{~m}^{2}\right)$ ], and ST is the soil thickness observed through the minirhizotron tubes (meters). Because ST value was reported to be $2 \mathrm{~mm}$ (Steele et al., 1997) and $3 \mathrm{~mm}$ (Itoh, 1985), the average of those two values was chosen, to wit $\mathrm{ST}=2.5 \times 10^{-3} \mathrm{~m}$. TRLD was estimated by total root (the roots that could be observed include white and brown roots) length divided by volume of soil, whereas total white root length density (WRLD) was estimated by total white root length divided by volume of soil.

DAta Processing. Because no roots were observed in the two deepest layers $(-150$ and $-200 \mathrm{~cm})$ before the last collection of images, only the RLD data for the first three soil layers $(0$ to $-100 \mathrm{~cm})$ were analyzed. The RF/BC and RF/ $\mathrm{SH} .40 / \mathrm{BC}$ trees in the south row replication were seriously damaged by diseases and insect pests; therefore, only the results of these two treatments in the north row are presented $(n=1)$. Data for scion/rootstock combinations other than $\mathrm{RF} / \mathrm{BC}$ and $\mathrm{RF} / \mathrm{SH} .40 / \mathrm{BC}$ were the average of the two replications $(\mathrm{n}=2)$. The drawback of less replicates was remedied by shortening the interval period of data collection to once every 2 weeks or $10 \mathrm{~d}$ to minimize the variation in measurements (Johnson et al., $2001)$. Data of the mean values of repeated observations $(n=$ 50) were statistically analyzed with SPSS 16.0 (IBM Corp., Armonk, NY) using Duncan's multiple range test at a level of significance of 0.05 .

\section{Results and Discussion}

The OCCURRENCE AND DEVelopment OF NEW ROOTS. Initially, no roots were visible in image fields, as presented in Figures $2 \mathrm{~A}$ and $2 \mathrm{~J}$. Then, roots appeared (Figs. $2 \mathrm{~B}$ and $2 \mathrm{~K}$ ) and grew longer or sometimes branched (Figs. $2 \mathrm{C}$ and $2 \mathrm{~L}$ ). The color of the roots varied from white to brown. The white roots were the newly developed ones. Some of the white roots remained white for several days (Fig. 2M), whereas some white roots turned partially brown, likely as a result of lignifications (Fig. 2D-E). Some white roots remained white for several days (Fig. $2 \mathrm{~K}-\mathrm{L}$ ), whereas some white roots turned partially brown and then disappeared (Fig. 2D-I) or turned light brown, likely as a result of lignifications (Fig. 2N), and gradually turned completely brown (Fig. 2O-R). Three developmental classifications for the roots were observed: 1) remained white; 2) disappeared; and 3) fully matured (brown roots). It took 30 to $40 \mathrm{~d}$ for a newly developed root to become permanently brown (Fig. 2). Some roots took several days, several months, or even more than one year to disappear (not shown), and therefore, the lifespan of the roots varied from several days to years in this study. Similar findings for root lifespan of tree species have been reported by Eissentat and Yanai (1997) and Zhang and Wu (2001).

A typical white root is a primary root attached to the other types of roots and is mainly responsible for mineral nutrition absorption, organic substances, and cytokinin synthesis. A typical brown root is a lignified lateral root and is mainly responsible for anchoring the tree and storing and transporting water and nutrients (Yang and Shu, 2006). There are two fates of newly formed roots in plants: developing into conducting roots or dying and decaying. The former type roots are referred to as extensive roots and the latter referred to as absorbing roots (Shu, 1999). It is impossible to identify these two types 

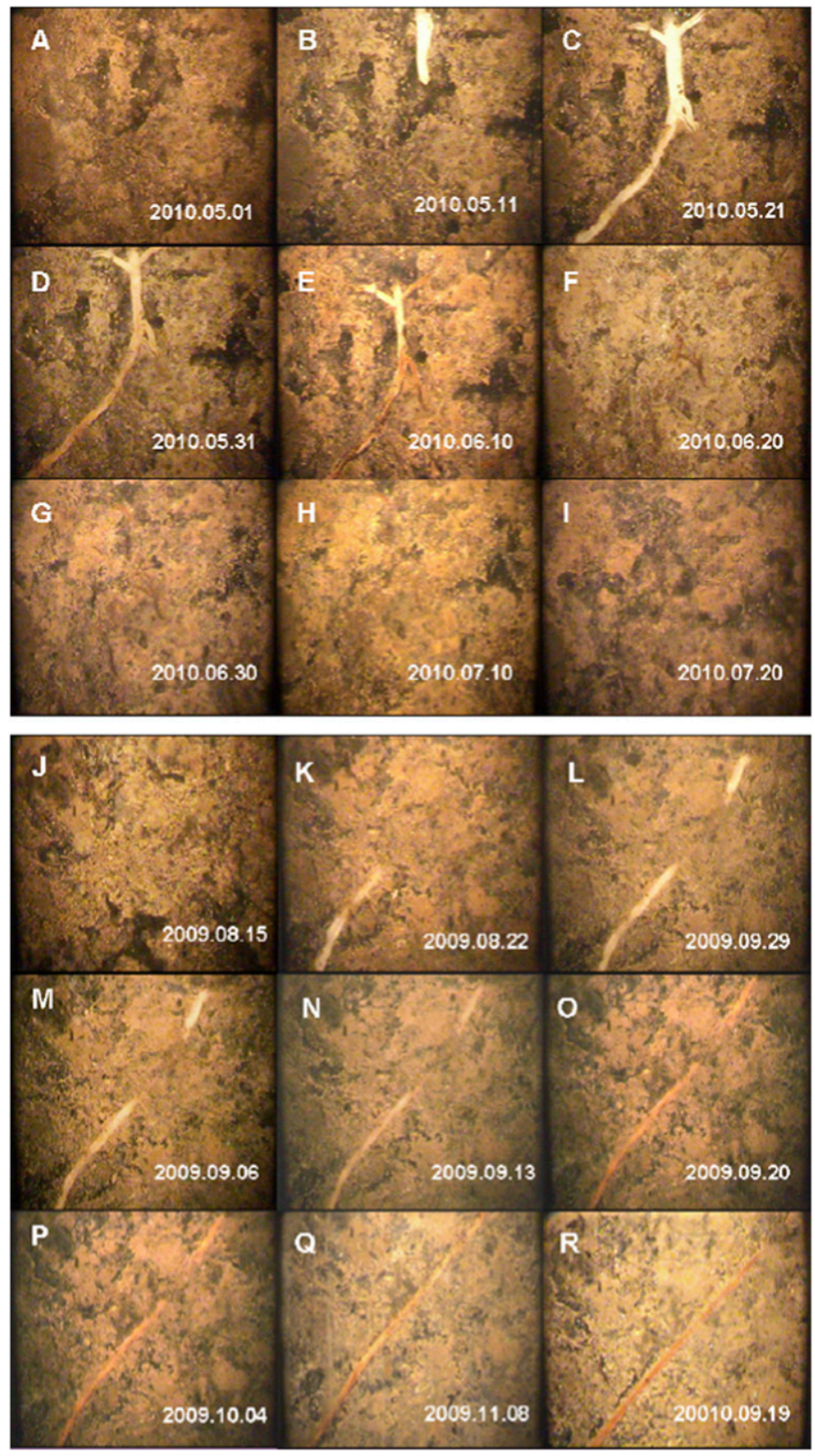

Fig. 2. Apple root growth in images from minirhizotrons. (A-I) Images in the same visible window demonstrating the growth of a root from appearance to gradual disappearance (1 May to 20 July 2010). (J-R) Images in the same visible window demonstrating the development of a young root as it matures (15 Aug. 2009 to 19 Sept. 2010). (A, J) No visible roots; (B, K) new roots appear; $(\mathbf{C}, \mathbf{L})$ roots become longer $(\mathbf{L})$ or branch $(\mathbf{C}) ;(\mathbf{M})$ roots remain white; $(\mathrm{D}-\mathbf{F}, \mathbf{N}-\mathbf{P})$ roots gradually turn brown or mature; $(\mathbf{G}-\mathbf{H})$ roots partially disappear, are not visible, or disappear; $(\mathbf{Q}-\mathbf{R})$ mature roots.

morphologically in the early stages of rhizogenesis, but most dead roots (disappeared roots) caused a decline in the TRLD (Fig. 3) in this study and were therefore likely to have been absorbing roots.

DYNAMICS OF TOTAL ROOT LENGTH DENSITY IN DIFFERENT SCION/ROOTSTOCK COMBINATIONS. The TRLD dynamics differed greatly among the scion/rootstock combinations (Fig. 3). In general, the greatest TRLD was found in $\mathrm{RF} / \mathrm{BC}$ followed in descending order by RF/SH.40/BC, RF/SH.40, and RF/M.9/BC and finally RF/M.9 (Table 2). The study of Garcia-Villanueva et al. (2004) showed that trees grafted on M.9 developed fewer

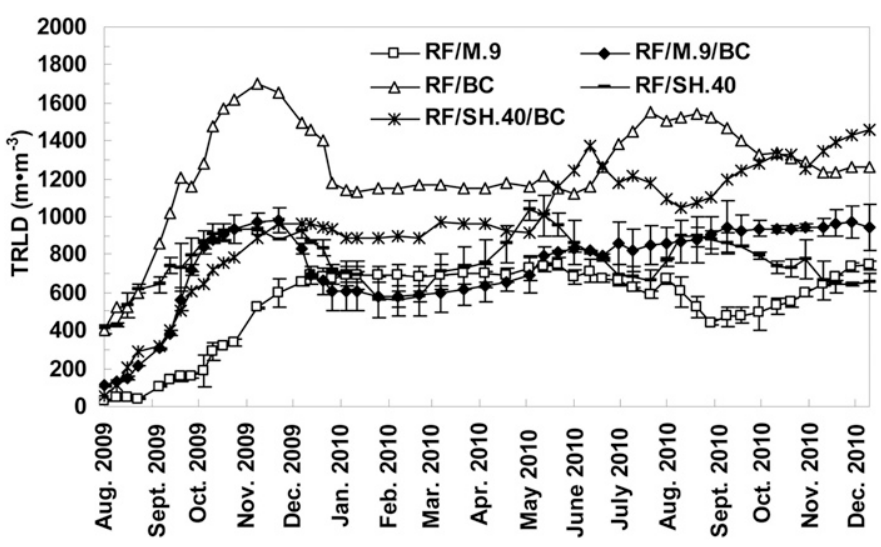

Fig. 3. Total root length density (TRLD) of apple trees in five scion/rootstock combinations ['Red Fuji' (RF)/“Baleng Crab' (BC), RF/“M.9' (M.9), RF/M.9/ BC, RF/Shao series no. 40 (SH.40), and RF/SH.40/BC] from Aug. 2009 (three months after transplanting) to Dec. 2010. The overall TRLD was the average of TRLD in three layers $(-20,-60$, and $-100 \mathrm{~cm})$. Data points in the line graphs are measurements taken from one replication per scion rootstock combination for $\mathrm{RF} / \mathrm{BC}$ and $\mathrm{RF} / \mathrm{SH} .40 / \mathrm{BC}$ and means of two replications per other scion/rootstock combinations and the vertical bars indicate SE $(n=2)$.

roots than own-rooted trees. The TRLDs of RF/M.9 and RF/ M.9/BC were generally very low. So we speculated that using M.9 rootstock or interstem might reduce the root production or shorten the lifespan of roots. The absorbing roots of M.9 can have a short lifespan (Garcia-Villanueva et al., 2004).

Previous research has shown that the annual dynamics of root growth vary with plant types. Single peaks, double peaks, and triple peaks in annual root growth have all been reported, and the peak in root growth may occur before the rapid growth of the shoot in the spring, during the vegetative termination stage in the summer, or after the shoot stops growing in the fall (Atkinson, 1980; Qu and Han, 1983; Wang, 2005; Wang et al., 1997). This study was conducted in a greenhouse where the environmental conditions were relatively stable. The results showed that the root dynamics were related to the scion/ rootstock combination and that the peaks occurred at different times with different combinations (Fig. 3).

The scion/rootstock combinations we examined exhibited single and double peaks of TRLD. The TRLD in the one RF/BC tree exhibited a typical single peak of annual root growth: the TRLD increased continually from early June, reaching its maximum in November of the first year and around August during the second year (Fig. 3). The roots that caused the TRLD decline after August might have been absorbing roots.

The TRLD in RF/SH.40 exhibited double peaks in annual root growth. The first peak in SH.40 both as a rootstock appeared earlier than that of the other combinations (Fig. 3). We speculate that the early timing of this peak may be related to the early phenophase of SH.40. The studies of Shao et al. (1991) on Shao (SH) series apple dwarfing stocks have shown that they flowered and fruited early in their life cycle, and cessation and leaf fall were also early. The RF/SH.40 had the earliest first peak of root growth in early May and a second peak of root growth that occurred almost simultaneously with the single peak of RF/BC (Fig. 3).

In RF/M.9, TRLD increases starting in early October each year and reached its maximum in early December. The maximum TRLD of RF/M.9 was sustained from December until the following June (Fig. 3). The greatest TRLD in RF/M.9/BC was 
Table 2. Mean total root length density (TRLD), total white root length density (WRLD), and shoot growth rate for five apple scion/rootstock combinations: 'Red Fuji' (RF)/‘M.9' (M.9), RF/M.9/'Baleng Crab’ (BC), RF/BC, RF/Shao series no. 40 (SH.40), and RF/SH.40/BC (n = 50).

\begin{tabular}{|c|c|c|c|c|c|}
\hline Variable & RF/M.9 & RF/M.9/BC & $\mathrm{RF} / \mathrm{BC}$ & RF/SH.40 & $\mathrm{RF} / \mathrm{SH} 0.40 / \mathrm{BC}$ \\
\hline$\overline{\operatorname{Avg}} \operatorname{TRLD}\left(\mathrm{m} \cdot \mathrm{m}^{-3}\right)$ & $525.41 \mathrm{~d}^{\mathrm{z}}$ & $731.88 \mathrm{c}$ & $1234.54 \mathrm{a}$ & $761.95 \mathrm{c}$ & $947.52 \mathrm{~b}$ \\
\hline \multicolumn{6}{|c|}{ TRLD by depth $\left(\mathrm{m} \cdot \mathrm{m}^{-3}\right)$} \\
\hline$-40 \mathrm{~cm}$ & $97.23 \mathrm{~d}$ & $886.42 \mathrm{~b}$ & $1298.82 \mathrm{a}$ & $624.80 \mathrm{c}$ & $547.11 \mathrm{c}$ \\
\hline$-60 \mathrm{~cm}$ & $29.03 \mathrm{c}$ & $283.57 \mathrm{~b}$ & $483.87 \mathrm{a}$ & $441.09 \mathrm{ab}$ & $309.35 \mathrm{~b}$ \\
\hline \multicolumn{6}{|c|}{ TRLD by region $\left(\mathrm{m} \cdot \mathrm{m}^{-3}\right)$} \\
\hline \multicolumn{6}{|c|}{ Shoot growth rate $\left(\mathrm{cm} \cdot \mathrm{d}^{-1}\right)$} \\
\hline 2009 & $1.64 \mathrm{bc}$ & $1.83 \mathrm{bc}$ & $6.72 \mathrm{a}$ & $0.60 \mathrm{~cd}$ & $2.50 \mathrm{~b}$ \\
\hline 2010 & $5.38 \mathrm{~b}$ & $8.98 \mathrm{~b}$ & $23.53 \mathrm{a}$ & $3.48 \mathrm{~b}$ & $11.32 \mathrm{~b}$ \\
\hline
\end{tabular}

${ }^{\mathrm{z}}$ Different letters indicate significant differences between scion/rootstock combinations by Duncan's multiple range test at $P<0.05$.

in late Nov. 2009, and the TRLD of RF/M.9/BC changed little during the second year of the trial (Fig. 3). The TRLD of M.9 as a rootstock or an interstem was generally lower than those of the other grafted combinations (Fig. 3) and their average TRLDs were significantly lower than $\mathrm{RF} / \mathrm{BC}$ (Table 2). The results were similar to previous studies that root growth alternated with shoot growth (Qu and Han, 1983; Wang, 2005). The greatest TRLD of RF/M.9 occurred in winter (Fig. 3). The low TRLD at fruiting period would contribute to reduce the carbohydrate transportation to roots and increase nutrition transportation to aerial parts, which can improve yield. Therefore, trees grafted onto M.9 can have high yield (Di Vaio et al., 2009).

DYNAMICS OF WHITE ROOT LENGTH DENSITY IN DIFFERENT SCION/Rootstock Combinations. Stages of root development were identified by color of roots. Newly generated roots were generally white (Fig. 2). An increase in new roots can offset roots that have disappeared from the visible field in TRLD; therefore, changes in WRLD may reflect root growth characteristics more clearly than TRLD. The average WRLD of all observation values showed the similar trend to that of TRLD (Table 2) except RF/M.9/BC < RF/M.9 in WRLD. The dynamics of WRLD were analyzed on different scion/rootstock combinations (Fig. 4). During the first growing season after the replanting of the trees, a large amount of white roots was observed in each treatment, and the greatest WRLD was observed in the one RF/BC tree (Fig. 4). In the second year, the greatest WRLD in RF/SH.40 and the one RF/SH.40/BC tree occurred in mid-April and mid-June, respectively, and the greatest WRLD in the one RF/BC tree occurred in August. The WRLD in RF/SH.40 and RF/SH.40/BC decreased in midMay and early August (Fig. 4), similar to the trend observed in TRLD for these rootstock/scion combinations (Fig. 3). In M.9 grafted combinations, the WRLD in RF/M.9 increased from mid-October to late November (Fig. 4). In contrast, RF/M.9/BC had little fluctuation in WRLD during the second year (Fig. 4), which was similar to the trend observed in TRLD for RF/M.9/ BC (Fig. 3). A previous study in a replanted orchard of apple trees showed that significant new root production occurs between May and July, then production of new roots decreased substantially by August, and then increased slightly in late October (Yao et al., 2006). In our study, the new root production occurred from May to December. The fine root observation on pear (Pyrus communis L.) with minirhizotrons showed that root production mainly occurs in late winter-spring and, with less

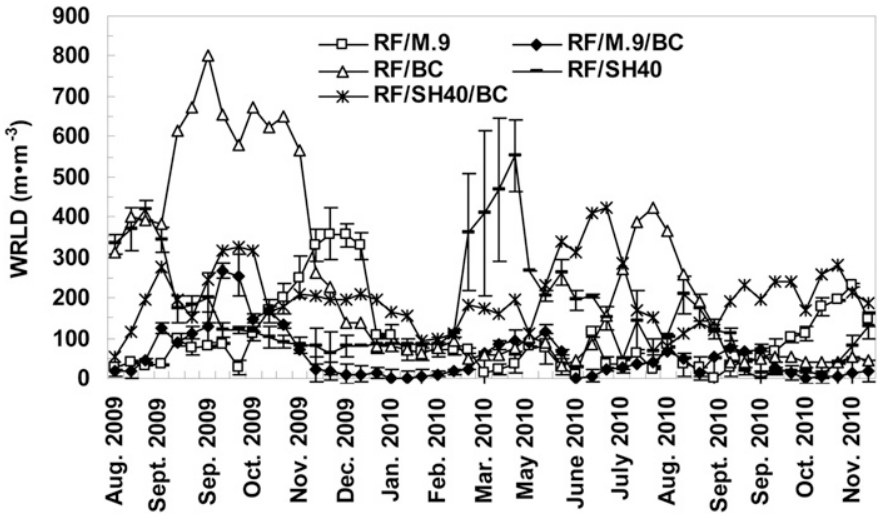

Fig. 4. White root length density (WRLD) of apple trees in five scion/rootstock combinations ['Red Fuji' (RF)/'Baleng Crab' (BC), RF/'M.9' (M.9), RF/ M.9/BC, RF/Shao series no. 40 (SH.40), and RF/SH.40/BC] from Aug. 2009 (three months after transplanting) to Dec. 2010. The overall WRLD was the average of WRLD in three layers $(-20,-60$, and $-100 \mathrm{~cm})$. Data points in the line graphs are measurements taken from one replication per scion rootstock combination for $\mathrm{RF} / \mathrm{BC}$ and $\mathrm{RF} / \mathrm{SH} .40 / \mathrm{BC}$ and means of two replications per other scion/rootstock combinations and the vertical bars indicate SE $(\mathrm{n}=2)$.

intensity, in fall (Quartieri et al., 2010). The WRLD peak we observed in winter in M.9 treatments as well as peaks in the TRLD for M.9 treatments may be a factor in the low cold tolerance of M.9 stock combinations (Bu et al., 2005).

DYNAMICS OF SHOOT GROWTH RATE IN DIFFERENT SCION/ ROOTSTOCK COMBINATIONS. The use of dwarfing rootstocks or interstems reduced aboveground vegetative growth (Fig. 5). The one $\mathrm{RF} / \mathrm{BC}$ tree generally had the greatest shoot growth and the shoot growth of dwarfing interstem treatment was greater than that of its rootstock treatment (Table 2). Similarly, the TRLD was greatest in RF/BC, smallest in dwarfing rootstock treatment (RF/SH.40 or RF/M.9), and intermediate in dwarfing interstem treatment (RF/SH.40/BC or RF/M.9/BC) (Table 2). Interestingly, the one $\mathrm{RF} / \mathrm{SH} .40 / \mathrm{BC}$ tree had greater shoot growth than RF/M.9/BC, whereas RF/SH.40 had lower shoot growth rate than RF/M.9 (Table 2). This suggests that SH.40 rootstock treatment, although with reduced aboveground vigor, had strong rhizogenesis potential. Maybe this is one of the reasons for the high drought tolerance and strong lodging resistance of SH series rootstocks (Shao et al., 1991). 

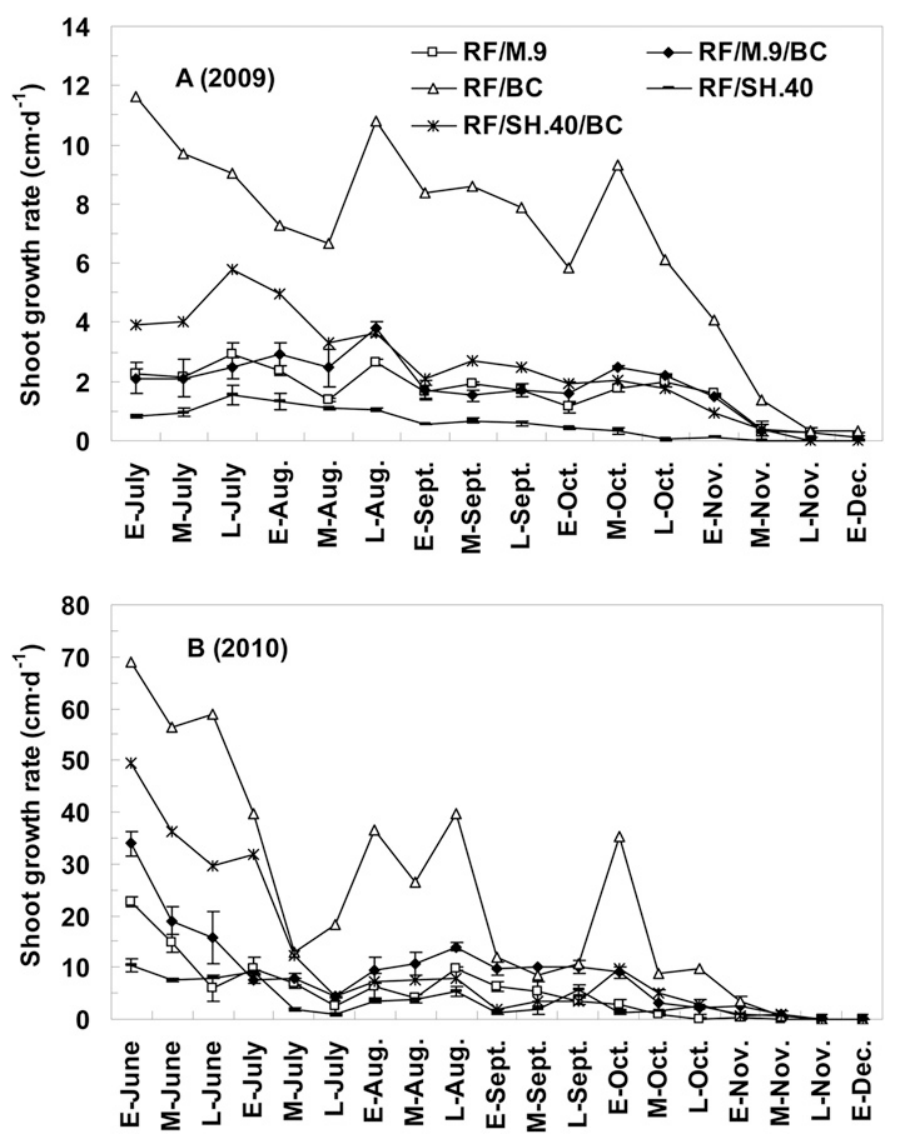

Fig. 5. Shoot growth rate dynamics of apple trees in (A) 2009 and (B) 2010 using five scion/rootstock combinations ['Red Fuji' (RF)/'Baleng Crab' (BC), RF/ 'M.9' (M.9), RF/M.9/BC, RF/Shao series no. 40 (SH.40), and RF/SH.40/BC] from July 2009 (one month after transplanting) to Dec. 2010; E-= early; M-= middle; $\mathrm{L}-=$ late. Data points in the line graphs are measurements taken from one replication per scion rootstock combination for $\mathrm{RF} / \mathrm{BC}$ and $\mathrm{RF} / \mathrm{SH} .40 / \mathrm{BC}$ and means of two replications per other scion/rootstock combinations and the vertical bars indicate SE $(n=2)$.

Data collected in 2009 (Fig. 5A) were collected during a transition period because trees were grafted and transplanted that year. In contrast, data from 2010 (Fig. 5B) indicate the shoots grew rapidly after pruning. Annually, three peaks of shoot growth were observed in the $\mathrm{RF} / \mathrm{BC}$ tree. The first peak occurred in early June and the other two peaks were in August and early October. The WRLD peaks of the one RF/BC tree occurred in late July (Fig. 4) between the first two peaks of annual shoot growth (Fig. 5). Three peaks of shoot growth were observed in the one RF/SH.40/BC tree. Timing of shoot growth in RF/SH.40/BC was similar to that observed in RF/BC except that the last two peaks in shoot growth were much smaller than in the one RF/BC tree. The two peaks of WRLD in RF/SH.40/ $\mathrm{BC}$ occurred in mid-June and November just after peaks of shoot growth (Figs. 4 and 5). There were two peaks of shoot growth in M.9 treatments (RF/M.9 and RF/M.9/BC), which occurred in early June and late August (Fig. 5) before their WRLD peaks (Fig. 4). In contrast, the WRLD peak in RF/ SH.40 was observed before the peak of shoot growth (Figs. 4 and 5).

For each treatment, the shoot growth rate decreased greatly after the first peak, and the remaining peaks in shoot growth were smaller (Fig. 5). Our results indicate that peaks of shoot

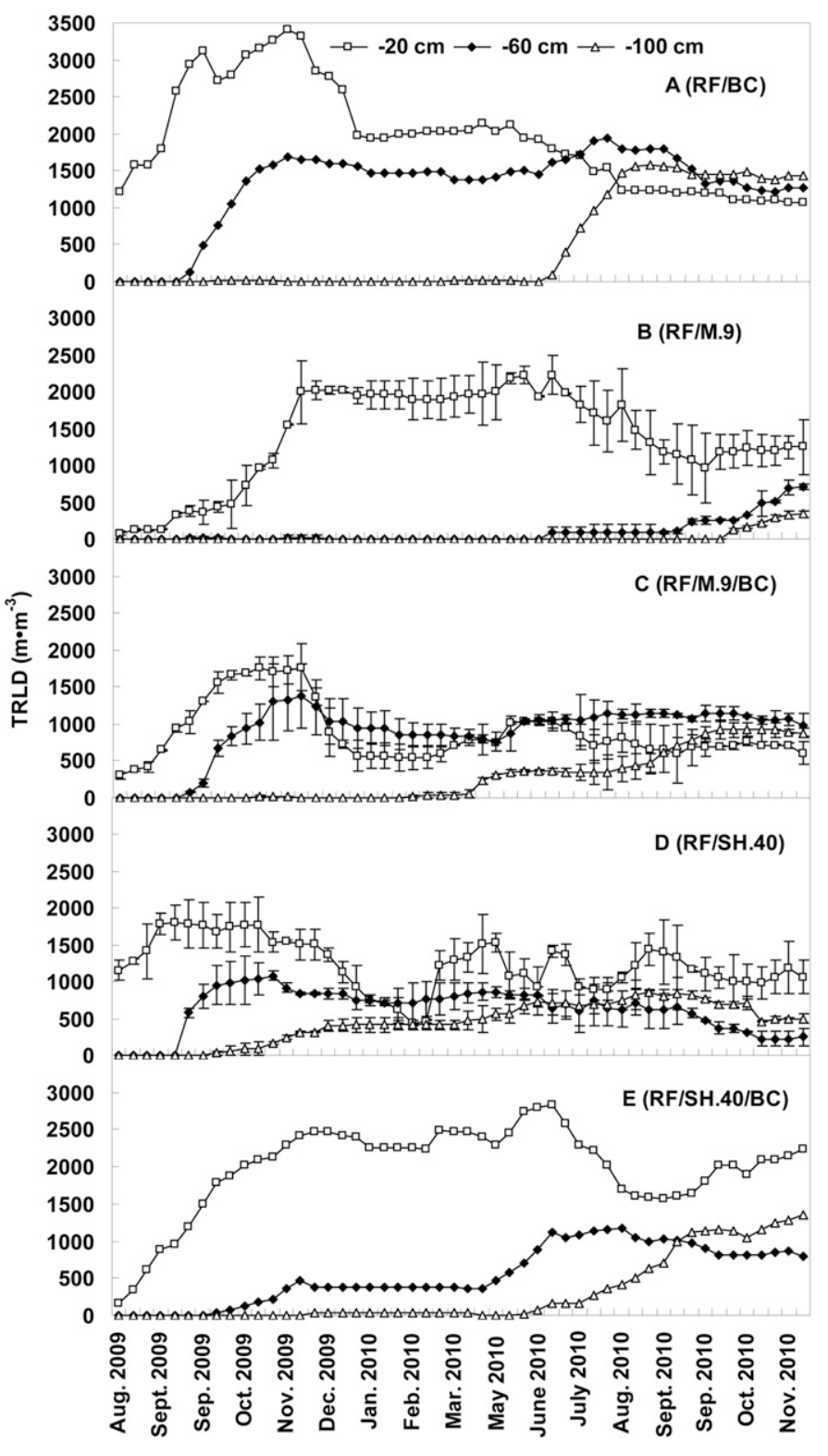

Fig. 6. Distribution of the total root length density (TRLD) in three soil layers $(-20,-60$, and $-100 \mathrm{~cm})$ of apple trees in five scion/rootstock combinations [(A) 'Red Fuji' (RF)/'Baleng Crab' (BC), (B) RF/'M.9' (M.9), (C) RF/M.9/ BC, (D) RF/Shao series no. 40 (SH.40), and (E) RF/SH.40/BC] from Aug. 2009 (three months after transplanting) to Dec. 2010. Data points in the line graphs are measurements taken from one replication per scion rootstock combination for RF/BC and RF/SH.40/BC and means of two replications per other scion/rootstock combinations and the vertical bars indicate $\operatorname{SE}(n=2)$.

growth occurred asynchronously with peaks in WRLD. The results were similar to previous studies that root growth alternated with shoot growth (Head, 1967; Qu and Han, 1983; Wang, 2005). This suggests that root and shoot are probably mutually linked to each other.

ROOT SPATIAL DISTRIBUTIONS OF DIFFERENT SCION/ROOTSTOCK combinations. The TRLD observed in different layers of minirhizotron tubes varied greatly among treatments (Fig. 6). In the one $\mathrm{RF} / \mathrm{BC}$ tree, rhizogenesis at $-20 \mathrm{~cm}$ occurred soon after transplanting, and rhizogenesis at $-60 \mathrm{~cm}$ occurred in Sept. 2009, four months after transplanting (Fig. 6A). Roots at $-100 \mathrm{~cm}$ grew very quickly in June 2010 (Fig. 6A). For RF/M.9, 
the roots reached to the $-20-\mathrm{cm}$ soil layer until the end of the first growing season, and the TRLDs at -60 and $-100 \mathrm{~cm}$ were still very low even during the next December (Fig. 6B).

The rhizogenesis of RF/SH.40 in the deep soil layer $(-100 \mathrm{~cm})$ occurred before that of any other scion/rootstock combination (Fig. 6D) within five months after transplanting, and the roots of RF/SH.40 had penetrated to a depth of $100 \mathrm{~cm}$ from the surface of the soil, indicating that the roots of RF/SH.40 had great ability to grow into the deep soil layer. The first peak of annual root growth of RF/SH.40 in 2010 (Fig. 3) mainly occurred at $-20 \mathrm{~cm}$. The SH.40 grafted combinations had strong basipetal ability in root development that may contribute to the strong drought tolerance and lodging resistance. The SH series rootstock was developed at the Shanxi Institute of Pomology located in the semiarid Loess Plateau of China, and drought tolerance and lodging resistance were taken into account as breeding objectives and indices (Shao et al., 1988).

Roots at each depth appeared at similar times in RF/M.9/BC (Fig. 6C), RF/SH.40/BC (Fig. 6E), and RF/BC (Fig. 6A). In all three treatments, RF/M.9/BC, RF/SH.40/BC, and RF/BC, rhizogenesis at $-20 \mathrm{~cm}$ occurred before 2 Aug. 2009, roots at $-60 \mathrm{~cm}$ depth were first observed in Sept. 2009, and roots at $-100 \mathrm{~cm}$ mainly appeared between April and June 2010. In addition, the TRLD values of the one RF/SH.40/BC tree were similar to those of RF/BC (Figs. 6A and 6E). Compared with the one RF/BC tree (Fig. 6A), the M.9 interstem (Fig. 6C) did not appear to alter when roots appeared in each soil layer (Fig. 6A), although RF/M.9/BC generally had lower TRLD than RF/BC (Fig. 3).

The average TRLD of all observation values in different scion/rootstock combinations (Fig. 7; Table 2) showed that the $\mathrm{RF} / \mathrm{BC}$ and RF/SH.40/BC trees had the greatest TRLD in the -20 -cm layer. The highest average TRLD was also expressed in the one $\mathrm{RF} / \mathrm{BC}$ tree in the -40 - or -60 - $\mathrm{cm}$ layer. Although the average TRLD in the one RF/SH.40/BC tree was significantly higher than RF/SH.40 in $-20-\mathrm{cm}$ layer, it was numerically lower than RF/SH.40 in -40 - or -60 -cm layer with no significant difference at the $P<0.05$ level. The average TRLD of the one RF/M.9 tree in $-20-\mathrm{cm}$ layer was significantly higher than RF/M.9/BC, but it was lowest in $-40-\mathrm{cm}$ layer or $-60-\mathrm{cm}$ layer. The one RF/M.9/BC tree showed similar average TRLD values in -20 - and -40 -cm layer.

TRLD values varied greatly among treatments in the peripheral region of the rhizobox (Table 2). This phenomenon was also observed in the central region of the rhizobox during 2009 , when the trees were only one year old and the roots were unlikely to have been fully developed. The difference in TRLD in the central region among treatments was smaller in 2010; furthermore, the TRLD values in the central region had little seasonal variation in 2010. In general, the average TRLD of all observation values of the one $\mathrm{RF} / \mathrm{BC}$ tree were higher than those of other treatments, and the TRLD of RF/BC in the peripheral region was generally greater than that in the central region (Fig. 7A; Table 2). Similar to RF/BC, the one RF/SH.40/ $\mathrm{BC}$ tree had significantly higher TRLD than those of other treatments in the peripheral region but in general had the second lowest TRLD value in the central region (Fig. 7E; Table 2). In contrast, TRLD in RF/M.9/BC (Fig. 7C) decreased with the radial distance. With RF/SH.40 (Fig. 7D), the rhizogenesis in the central region occurred slightly earlier than that of the other graft combinations, and the TRLD in the central region was greater than that in the peripheral region in 2009.

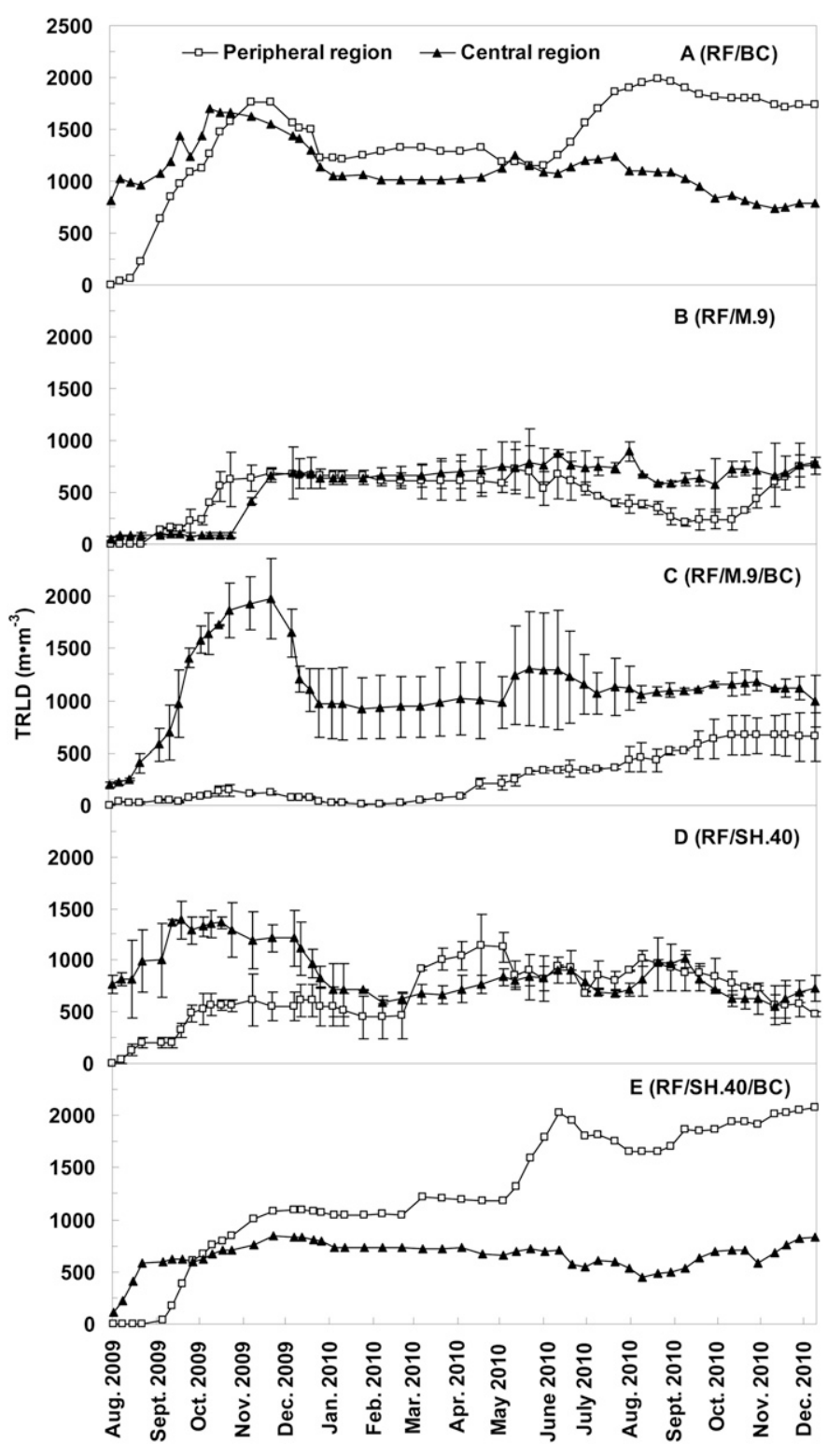

Fig. 7. Distribution of the total root length density (TRLD) in two regions at different radial distances from stems of apple trees in five scion/rootstock combinations [(A) 'Red Fuji' (RF)/'Baleng Crab' (BC), (B) RF/'M.9' (M.9), (C) RF/M.9/BC, (D) RF/Shao series no. 40 (SH.40), and (E) RF/SH.40/BC] from Aug. 2009 (three months after transplanting) to Dec. 2010. The central region was $18.75 \mathrm{~cm}$ from the stem. The peripheral region was $56.25 \mathrm{~cm}$ from the stem. Data points in the line graphs are measurements taken from one replication per scion rootstock combination for $\mathrm{RF} / \mathrm{BC}$ and $\mathrm{RF} / \mathrm{SH} .40 / \mathrm{BC}$ and means of two replications per other scion/rootstock combinations and the vertical bars indicate SE $(n=2)$.

As the plants grew, the TRLDs at the two radial distances appeared to be similar in 2010 for RF/M.9 (Fig. 7B). Using M.9 as the rootstock (Fig. 7B), the TRLDs in both regions were generally lower than those of the one $\mathrm{RF} / \mathrm{BC}$ tree (Fig. 7A). The temporal dynamics of TRLD in peripheral and central regions on RF/M.9 were similar. Observation on the radial distributions of the root system allowed us to classify root system architecture into three categories: 1) RF/BC and RF/SH.40/BC with high TRLD in the peripheral region and relatively low TRLD in the central region; 2) RF/M.9/BC with more roots in the central region than the peripheral region; and 3) RF/SH.40 and RF/M.9 
with an intermediate type of root distribution that is relatively even over the radial distance in the observed region.

The root system of RF/M.9 was mainly in a shallow layer (Figs. 6B and 7B). The anchoring capacity and drought tolerance of apple trees grafted onto M.9 is thus poorer than those of trees grafted on vigorous rootstocks (Parry and Rogers, 1968). The roots at the different depths may be responsible for different functions; e.g., roots at 0 to $-20 \mathrm{~cm}$ exuded more $\mathrm{H}^{+}$ than those at -20 to $-40 \mathrm{~cm}$, and the roots in $0-$ to $-20-\mathrm{cm}$ depth had a high $\mathrm{NO}_{3}{ }^{-}$uptake rate in five-year-old 'Starkrimson'/ M. ×micromalus trees (Lu and Shu, 2009). Trees grafted onto M.9 had high yield (Di Vaio et al., 2009), which may the result of the rich shallow roots that are propitious for absorption and use of mineral nutrients. Growth tediousness (developing excessive organs) is a result of natural selection by competition and is detrimental to high yield (Sheng, 1990; Zhang and Jiang, 2000), and therefore the M.9 rootstock might also regulate the nutritional supply to the fruit and increase production by reducing the root growth tediousness (Mandre et al., 1995; Mataa and Tominaga, 1998; Yang et al., 2001). The vertical root distribution of the M.9 interstem treatment resembled that of RF/SH.40, but the horizontal distribution of TRLD in RF/ $\mathrm{M} .9 / \mathrm{BC}$ was concentrated in the central region and was much sparser in the peripheral region (Figs. 6C and 7C).

ROOT ARCHITECTURE OF APPLE TREES IN DIFFERENT SCION/ ROOTSTOCK COMBINATIONS. Root architecture is concerned with the entire root system or a large subset of the root system. In this text, it refers to the spatial configuration of the root system of an individual plant. Data describing the horizontal and vertical distributions of the TRLD of apple trees grafted onto three rootstocks (BC, M.9, and SH.40) and two interstems (M.9 and $\mathrm{SH} .40$ on $\mathrm{BC}$ ) indicate the root architectures varied with different rootstocks or interstems.

The one $\mathrm{RF} / \mathrm{BC}$ tree exhibited root architecture with the widest and deepest distribution (Figs. 6 and 7) and the greatest TRLD (Fig. 3). The root architecture of RF/M.9 was generally the smallest (Fig. 3), and its vertical distribution was the shallowest (Fig. 6B). Trees of RF/SH.40 generally had lower TRLD compared with RF/BC (Fig. 3), and its horizontal distribution was smaller than that of $\mathrm{RF} / \mathrm{BC}$ but its vertical distribution was similar to $\mathrm{RF} / \mathrm{BC}$ (Figs. 6D and 7D). In comparison with $\mathrm{RF} / \mathrm{BC}$, the insertion of M.9 and SH.40 interstems changed the root spatial distribution (Figs. 6 and 7). In general, RF/M.9/BC generally had significantly lower TRLD in the peripheral region than RF/BC, whereas RF/SH.40/ $\mathrm{BC}$ generally had significantly lower TRLD in the central region than $\mathrm{RF} / \mathrm{BC}$ (Table 2 ).

Previous studies showed that dwarf interstems grafted between the scions and rootstocks may reduce the tree vigor and root system size, similar to the trees when these genotypes are used as rootstocks compared with vigorous rootstock (Di Vaio et al., 2009; Rogers and Beakbane, 1957; Samad et al., 1999). The M.9 and SH.40 rootstocks and interstems reduced the TRLD compared with RF/BC (Fig. 3), consistent with previous results (Rogers and Beakbane, 1957; Samad et al., 1999). We propose that the M.9 and SH.40 interstems altered the root architecture by affecting both the root quantity and the root distribution. In RF/M.9/BC, the distribution of roots in different soil layers was similar to $\mathrm{RF} / \mathrm{BC}$, but the roots were sparse and the RLD decreased when M.9 was grafted between the scion and $\mathrm{BC}$ rootstock (Figs. 3 and 6). In RF/SH.40, the distribution pattern resembled that of $\mathrm{RF} / \mathrm{SH} .40 / \mathrm{BC}$, and the RLD resembled that of $\mathrm{RF} / \mathrm{BC}$ (Figs. 3, 6, and 7). Our data demonstrate that the root system of apple trees grafted with dwarfing interstems developed into an intermediate type of vigorous seedling rootstocks and dwarfing rootstocks. Additionally, our data suggest root architecture may be an important breeding index for apple rootstock breeding, as has been proved in rice (Oryza sativa L.) (Cai et al., 2005; Fan et al., 2002).

\section{Conclusions}

The dynamics of RLD in apple were found to have a great range. Depending on the rootstock or interstem used with the apple cultivar, one or two peaks in root growth were observed from May to December. Compared with just vigorous rootstock, using a dwarf interstem decreased the root growth and using a dwarf rootstock further decreased the root growth. The peaks in root growth occurred much earlier when SH.40 was used as the rootstock compared with other grafted combinations. Shoot and root growth occurred asynchronously. When M.9 was used as the rootstock, the root system was shallow, whereas it was deep when SH.40 was used as the rootstock. The use of a combination including a dwarfing interstem on a vigorous rootstock allowed the development of a wider or deeper root system than the use of only a dwarfing rootstock, although the root systems of dwarfing interstem grafted combinations were still less vigorous than those of vigorous rootstocks used without a dwarfing interstem.

\section{Literature Cited}

Atkinson, D.J. 1980. The distribution and effectiveness of the roots of tree crops. Hort. Rev. 2:424-490.

Bu, Q.Y., Y.Q. Zhou, Y.W. Xu, and F. Yang. 2005. Study progress in chill-resistance of apple trees. Northern Fruits 2:1-4.

Cai, K.Z., S.M. Luo, and S.S. Duan. 2005. The relationship between root system of rice and aboveground characteristics and yield. Hua Nan Nong Ye Da Xue Xue Bao 26:1-4.

De Silva, H.N., A.J. Hall, D.S. Tustin, and P.W. Gandar. 1999. Analysis of distribution of root length density of apple trees on different dwarfing rootstocks. Ann. Bot. (Lond.) 83:335-345.

Di Vaio, C., C. Cirillo, M. Buccheri, and F. Limongelli. 2009. Effect of interstock (M.9 and M.27) on vegetative growth and yield of apple trees (cv 'Annurca'). Sci. Hort. 119:270-274.

Eissentat, D.M. and R.D. Yanai. 1997. The ecology of root lifespan. Adv. Ecol. Res 27:1-60.

Fan, X.L., Z.J. Shi, and P. Wu. 2002. Effects of nitrogen fertilizer on parameters of rice (Oryza sativa L.) root architecture and their genotypic difference. J. Northwest Sci.-Technol Univ. Agr. For. (Natural Sci. Ed.) 30:1-5.

Gandar, P.W. and K.A. Hughes. 1988. Kiwifruit root systems. 1. Rootlength densities. N.Z. J. Expt. Agr. 16:35-46.

Garcia-Villanueva, E., E. Costes, and C. Jourdan. 2004. Comparing root and aerial growth dynamics of two apple hybrids ownrooted and grafted on M.9. Acta Hort. 658:61-68.

Goedegebure, J. 1978. Business-economic aspects of high density plantings in the Netherlands. Acta Hort. 65:21-29.

Head, G.G. 1967. Effect of seasonal changes in shoot growth of the amount of unsuberized root on apple and plum trees. J. Hort. Sci. 42:169-180.

Hodge, A., G. Berta, C. Doussan, F. Merchan, and M. Crespi. 2009. Plant root growth, architecture and function. Plant Soil 321:153-187. Hughes, K.A. and P.W. Gandar. 1993. Length densities, occupancies and weights of apple root systems. Plant Soil 148:211-221.

Itoh, S. 1985. In situ measurement of rooting density by microrhizotron. Soil Sci. Plant Nutr. 31:653-656. 
Jackson, J.E. 1989. World-wide development of high density planting in research and practice. Acta Hort. 243:17-27.

Johnson, M.G., D.T. Tingey, D.L. Phillips, and M.J. Storm. 2001. Advancing fine root research with minirhizotrons. Environ. Exp. Bot. 45:263-289.

Li, R.F., Y.R. Liang, Q.X. Jiang, X.H. Hu, S.L. Wang, L. Liang, and H.F. Qin. 2004. Experiment on apple hardy dwarfing rootstock. Acta Agr. Boreali-Sinica 19:114-118.

Lu, D.G. and H.R. Shu. 2009. Structure, function and effect of medium of root system in apple, p. 67-93. In: Shu, H.R. (ed.). Fruit cultivation: Theories \& applications. China Agr. Press, Beijing, China.

Ma, B.K., J.Z. Xu, and J.S. Sunday. 2010. Consideration for high density planting with dwarf rootstocks in apple in China. J. Fruit Sci. 27:105-109.

Majdi, H. and P. Kangas. 1997. Demography of fine roots in response to nutrient applications in a norway spruce stand in southwestern Sweden. Ecoscience 4:199-205.

Malamy, J.E. 2005. Intrinsic and environmental response pathways that regulate root system architecture. Plant Cell Environ. 28:67-77. Mandre, O., M. Rieger, S.C. Myers, R. Seversen, and J. Regnard. 1995. Interaction of root confinement and fruiting in peach. J. Amer. Soc. Hort. Sci. 120:282-284.

Mataa, M. and S. Tominaga. 1998. Effects of root restriction on tree development in Ponkan mandarin (Citrus reticulata Blanco). J. Amer. Soc. Hort. Sci. 123:651-655.

Matamala, R., M.A. Gonzalez-Meler, J.D. Jastrow, R.J. Norby, and W.H. Schlesinger. 2003. Impacts of fine root turnover on forest NPP and soil C sequestration potential. Science 302:1385-1387.

Norelli, J.L., H.T. Holleran, W.C. Johnson, T.L. Robinson, and H.S. Aldwinckle. 2003. Resistance of Geneva and other apple rootstocks to Erwinia amylovora. Plant Dis. 87:26-32.

Parry, M.S. and W.S. Rogers. 1968. Dwarfing interstocks: Their effect on the field performance and anchorage of apple trees. J. Hort. Sci. 43:133-146.

Pregitzer, K.S., J.L. DeForest, A.J. Burton, M.F. Allen, R.W. Ruess, and R.L. Hendrick. 2002. Fine root architecture of nine North American trees. Ecol. Monogr. 72:293-309.

Qu, Z.Z. and Q.Q. Han. 1983. Studies on the relationship between root and top growth of apple. Acta Hort. Sinica 10:25-33.

Quartieri, M., G. Castellani, E. Baldi, B. Marangoni, and M. Tagliavini. 2010. Fine roots growth and longevity in a high-density pear orchard in quince c rootstock as affected by nitrogen supply. Acta Hort. 868: $149-154$.

Rogers, W.S. and A.B. Beakbane. 1957. Stock and scion relations. Annu. Rev. Plant Physiol. 8:217-236.

Samad, A., D.L. McNeil, and Z.U. Khan. 1999. Effect of interstock bridge grafting (M9 dwarfing rootstock and same cultivar cutting) on vegetative growth, reproductive growth and carbohydrate composition of mature apple trees. Sci. Hort. 79:23-38.

Sarwar, M., R.M. Skirvin, M. Kushad, and M.A. Norton. 1998. Selecting dwarf apple (Malus $\times$ domestica Borkh.) trees in vitro: Multiple cytokinin tolerance expressed among three strains of 'McIntosh' that differ in their growth habit under field conditions. Plant Cell Tissue Organ Cult. 54:71-76.
Shao, K.J., D.K. Li, and Z.R. Zhang. 1988. A study on the breeding of apple dwarfing rootstock SH series. Acta Agr. Boreali Sinica 3:86-93.

Shao, K.J., D.K. Li, Z.R. Zhang, and X.M. Gao. 1991. A study on the characters and physiological traits of SH series apples dwarf stocks. Acta Hort. Sinica 18:289-295.

Sheng, C.F. 1990. Growth tediousness as an explanation of overcompensation of crops for insect feeding. J. Appl. Ecol. 1:26-30.

Shu, H.R. 1999. Apple science. China Agriculture Press, Beijing, China. Steele, S.J., S.T. Gower, J.G. Vogel, and J.M. Norman. 1997. Root mass, net primary production and turnover in aspen, jack pine and black spruce forests in Saskatchewan and Manitoba, Canada. Tree Physiol. 17:577-587.

Tufekcioglu, A., J. Raich, T. Isenhart, and R. Schultz. 1999. Fine root dynamics, coarse root biomass, root distribution, and soil respiration in a multispecies riparian buffer in central Iowa, USA. Agrofor. Syst. 44:163-174.

Vogt, K.A., D.J. Vogt, and J. Bloomfield. 1998. Analysis of some direct and indirect methods for estimating root biomass and production of forests at an ecosystem level. Plant Soil 200:71-89.

Wang, C.D., F.G. Diao, and G.Y. Fu. 1994. The technique of garden establishment for apple stock in semiarid region. J. Shanxi Agr. Sci. 22:60-61.

Wang, C.Q. 2005. Growth rule of year-on and year-off apple trees and recommended cultivation practices. J. Shanxi Agr. Sci. 33:35-39.

Wang, L.Q., Q.P. Wei, F. Tang, and H.R. Shu. 1997. Annual dynamic pattern of new roots of apple trees. J. Shandong Agr. Univ. 28:8-14.

Welander, M. 1988. Plant-regeneration from leaf and stem segments of shoots raised in vitro from mature apple-trees. J. Plant Physiol. 132:738-744.

Werth, K. 1978. Economics of high density planting in South Tyrol. Acta Hort. 65:47-52.

Werth, K. 1981. Development and current achievements of high density plantings in Italy, Switzerland, Austria and Yugoslavia. Acta Hort. 114:295-299.

Wu, L., M.B. McGechan, C.A. Watson, and J.A. Baddeley. 2005. Developing existing plant root system architecture models to meet future, agricultural challenges. Adv. Agron. 85:181-219.

Xiao, C.W., W.G. Sang, and R.Z. Wang. 2008. Fine root dynamics and turnover rate in an Asia white birch forest of Donglingshan Mountain, China. For. Ecol. Mgt. 255:765-773.

Yang, H., L. Li, and Y. Jie. 2001. Root restriction of horticultural plant and its application. Acta Hort. Sinica 28:705-710.

Yang, H.Q. and H.R. Shu. 2006. Researches on apple root. Science Press, Beijing, China.

Yao, S.R., A. Merwin, and M.G. Brown. 2006. Root dynamics of apple rootstocks in a replanted orchard. HortScience 41:1149-1155.

Zhang, D.Y. and X.H. Jiang. 2000. An ecological perspective on crop production. Acta Phytoecol. Sin. 24:383-384.

Zhang, X.Q. and K.H. Wu. 2001. Fine root production and turnover for forest ecosystem. Scientia Silvae Sinicae 37:126-138.

Zhang, X.Q., K.H. Wu, and D. Murach. 2000. A review of methods for fine-root production and turnover of trees. Acta Ecol. Sin. 20:875883. 